\title{
Archives in a changing climate: proposing new "solutions" for a new era
}

\author{
Viviane Frings-Hessami ${ }^{1}$ (D) Fiorella Foscarini ${ }^{2}$
}

Published online: 16 July 2019

(c) Springer Nature B.V. 2019

The International Conference on the History of Records and Archives (I-CHORA) has been held since 2003 as a periodic conference aimed at encouraging and promoting interdisciplinary research into the history of records, recordkeeping practices and recordkeeping institutions. Conferences to date have taken place in Toronto (2003), Amsterdam (2005 and 2015), Boston (2007), Perth (2008), London (2010) and Austin (2012), each attracting between 100 and 130 scholars and professionals from around the world (Foscarini et al. 2016, pp. xi-v). The eighth iteration, I-CHORA 8, was held at Monash University in Melbourne on 28-30 May 2018. The theme of the conference was "Archives in a Changing Climate" (http://ichora.org/). Participants discussed the multiplicity of historical contexts in which archives are created, transmitted, preserved and reactivated, and the fast pace of change to which contemporary recordkeepers have to adjust to keep up with new technologies and new expectations.

In the first of two special issues of Archival Science dedicated to papers from I-CHORA 8, we present four articles that propose new "solutions", or better, aspirations, for a new era in archives and recordkeeping. The first contribution by Jessica Lapp suggests a way of rethinking the role played by archivists, whereas the other three articles, by Cate O'Neill, Viviane Frings-Hessami, and Sue McKemmish, Tom Chandler and Shannon Faulkhead, offer ways of reframing recordkeeping practices that focus on the rights of the subjects of the records.

In 2007, Terry Cook wrote:

until the 1980s, archivists, at least in Canada, often described themselves - proudly - as the 'handmaidens of historians'. In retrospect, that phrase is astonishing for its servility and its gender connotations. Until recently, women

Viviane Frings-Hessami

viviane.hessami@monash.edu

Fiorella Foscarini

fiorella.foscarini@utoronto.ca

1 Faculty of Information Technology, Centre for Social and Organisational Informatics, Monash University, P.O. Box 197, Caulfield East, VIC 3145, Australia

2 Faculty of Information, University of Toronto, Toronto, Canada 
remained largely invisible in social and historical memory, relegated as the silent and usually unrecognized supporters of male accomplishments; so too, archivists have remained invisible in the construction of social memory, their role also poorly articulated and rarely appreciated (Cook 2007, p. 170).

In her article, Lapp uses the "handmaidens of history" metaphor as a tool for exploring how archival work, once considered "mechanical, servile and invisible", has become "powerful and disruptive, offering opportunities for political intervention and social change". Reflecting on the shift from portraying the archivist as a passive and invisible caretaker to thinking of the archivist as an active shaper of history, Lapp argues that a feminist ethics of care allows reconceptualising archival work as a radical act, and that the metaphor of the handmaiden can be used to describe that shift. Referring to Margaret Atwood's dystopian novel, The Handmaid's Tale, she argues that handmaidens may be perceived as passive and demure, but underneath they are disruptive and powerful. The handmaiden metaphor helps to reveal the other world of labour and care beneath the apparent subservient status of the archivists. The archivist role can then be turned into a feminist role that transforms the apparent weaknesses of the old image into new strengths that can be used in furthering social change.

The other three articles propose turning to the rights of the subjects of the records as a way to imbue archival work and the archivist role with new meanings. A key reference for this discussion is the set of rights in records developed by Gilliland and McKemmish (2015) in order to ensure that descriptive practices, access and disclosure processes "do not expose or exploit those who are vulnerable to suppression, appropriation, violence, discrimination, or other oppressive or traumatizing acts, or re-traumatize them" (p. 120). O’Neill, Frings-Hessami and McKemmish et al. illustrate in three very different contexts the importance of consulting "with the creators and co-creators/subjects of archival materials when appraising, arranging materials, developing descriptions, and making decisions about access and disclosure" (Gilliland and McKemmish 2015, p. 120).

Both O'Neill and Frings-Hessami's contributions were included in the "Displacement and Return" session at the I-CHORA 8 conference, while McKemmish, Chandler and Faulkhead's article is based on McKemmish's closing keynote speech, and also addresses dislocation and return issues. All three articles explore what happens when records are disconnected from the wider context of their creation when they are preserved in archival institutions, and offer insights on how to better meet the needs of the subjects of the records and their communities through archival practices. They suggest that this goal can be achieved by providing wider access to the records - in the case of Care Leavers records (O'Neill); imposing access restrictions to records that include personal information about third parties-in the case of Khmer Rouge records (Frings-Hessami); and designing a new way of accessing and interacting with records that re-embed them in their communities-in the case of Indigenous records (McKemmish et al.).

O'Neill looks at the administrative and financial records relating to the payment of children benefits, known as child endowment, by the Australian Commonwealth Government between 1941 and 1976 (Find and Connect 2018). Documents relating 
to the payment of child endowment to institutions looking after children who had been removed from their families were preserved in correspondence files that have been transferred to the National Archives of Australia (NAA). These records can be extremely valuable since they sometimes provide the only evidence that children lived in those institutions. They contain the names of children and their parents, dates of admission and discharge, and valuable contextual information on the organisations. Therefore, they can help Care Leavers to reconstruct a narrative about their childhood. In the 2000s, following pressure from Care Leavers advocacy groups, NAA reappraised some series of records to acknowledge their importance to Care Leavers, changing their retention period to permanent and their access status to open access, as well as digitising some files and making them available online.

O'Neill bases her analysis on the Repurposed Archive Continuum Model developed by Frings-Hessami (2018) which adds a "Reclaim" dimension to the four dimensions of the Records Continuum Model to accommodate the processes that must take place when organisational records are reclaimed by Care Leavers. The child endowment payment records provide an example of records that have been repurposed following pressures from Care Leavers advocacy groups. Care Leavers advocacy groups, in particular the Care Leavers Australasia Network (CLAN), used the existence of these records as evidence of the Commonwealth Government's involvement in supporting welfare institutions that accommodated children (which were under the responsibility of the state governments) to argue that the federal government has a responsibility to address the wrongs that were done to children in those institutions. These external pressures resulted in records being located, reappraised, redescribed and repurposed before being made available to Care Leavers and other interested users. These reuses of the records, which could not have been foreseen when they were created, show how archives can be repurposed following external pressures to meet the needs of new stakeholders with pressing needs for the records.

Frings-Hessami's study of Khmer Rouge archives illustrates how determining whose rights are affected by an archive can be a complex question. She goes beyond the rights of the victims of the Khmer Rouge as subjects and "co-creators" of the records that were compiled about them, to encompass the rights of the people who are mentioned in the records, as secondary victims who can be (re-)traumatised and discriminated against when records are made widely accessible. She shows that Khmer Rouge archives containing "confessions" extracted under torture were made publicly accessible and reused without consideration for the privacy of the victims and the people who were reported as "co-conspirators" in those "confessions".

Frings-Hessami argues that displacement and return are intellectual concepts and that archives which have been managed in accordance with foreign values and concepts were displaced from their cultural context and should be rethought and redesigned to reflect the culture and the values of the communities affected by the records. She contends that the use and reuse of an archive should conform to the traditions and beliefs of the people affected by the archive, in particular the subjects of the records and their communities who can be viewed as co-creators of those records. She suggests that an ethical, culturally based use of the archive should be driven by respect for the subjects of the records, respect for the local culture and 
sensitivities and respect for any future uses of the records wished for by the local people. She argues that the "commercial, uninformed and culturally insensitive exploitation" of the archive should be restricted, and that "in order to decolonise the archive, we must put at the centre the interests of the subjects of the records, including those of third parties mentioned in the records, rather than the interests of foreign researchers" as has been the practice since the Khmer Rouge archives were discovered, reconstructed and managed to support political interests.

In the last article included in this special issue, McKemmish et al. challenge the traditional collecting archive model, which "disembeds records from their living contexts" to preserve them in institutional settings and which, in the case of Australian Indigenous records, in practice amounts to a "continuing colonization of knowledge structures". They propose instead new forms of archives that reconnect with Indigenous cultures back through time. They envisage to embed, or re-embed, Indigenous records which have been dispersed in the country they are associated with, and to reconnect them with the tangible and intangible records of place and people that still exist there. Taking the Monash Country Lines Archive as an example of a participatory archive, where Australian Indigenous communities are involved in cocreating 3D animations of Indigenous stories with the aim of preserving Indigenous languages and cultures, McKemmish et al. show how to bring together Indigenous and non-Indigenous partners, community and academics in a "co-creative journey of reconciling research". They propose to use augmented reality and virtual reality as ways to reconnect to country back through time, by overlaying the physical world with text, images and 3D models that could be accessed through mobile devices such as smart phones or tablets. This is seen as a way to restore Indigenous peoples' connections with their land, culture, spirituality and ancestry, and thus contribute to their healing and wellbeing.

Much of the recent discourse on decolonising the archive focuses on the role to be played by archivists, on the "agency of the archivist" in "[r]e-crafting and reinterpreting archival processes" (Bastian 2019, p. 206). The articles in this special issue emphasise this new role of the archivists as well as the fundamental roles the subjects of the records and their advocates play in applying pressures to bring change into the archive. All four articles propose new "solutions" for a new era in archives and recordkeeping. Each suggested way forward places the people, rather than the records, at the centre of the discussion, is designed to meet the particular needs of the people affected by the records, and highlights the immense responsibility archivists have in this transformative process.

\section{References}

Bastian J (2019) Epilogue. On Augusta's porch; a meditation on decolonizing the archives. Arch Sci 19(2):205-207

Cook T (2007) Remembering the future: appraisal of records and the role of archives in constructing social memory. In: Blouin FX, Rosenberg WG (eds) Archives, documentation and institutions of social memory: essays from the Sawyer Seminar. University of Michigan Press, Ann Arbor, pp $169-182$ 
Find \& Connect (2018) Child endowment (1941-1946). https://www.findandconnect.gov.au/guide/austr alia/FE00135. Accessed 16 June 2019

Foscarini F, MacNeil H, Mak B, Oliver G (2016) Editor's introduction. In: Foscarini F et al (eds) Engaging with records and archives: histories and theories. Facet, London, $\mathrm{p} x \mathrm{x}-\mathrm{XV}$

Frings-Hessami V (2018) Care Leavers' records: a case for a repurposed archive continuum model. Arch Manuscr 46(2):158-173

Gilliland AJ, McKemmish S (2015) Rights in records as a platform for participatory archiving. In: Cox RJ, Langmead A, Mattern E (eds) Archival education and research: selected papers from the 2014 AERI conference. https://escholarship.org/uc/item/5g3135n6. Accessed 16 June 2019

Publisher's Note Springer Nature remains neutral with regard to jurisdictional claims in published maps and institutional affiliations.

Viviane Frings-Hessami is a lecturer in the Centre for Organisational and Social Informatics at Monash University, Melbourne, Australia, where she teaches the Archives and Recordkeeping units. She holds a Ph.D. in Political Science from Monash University and an MA in South East Asian Studies from the University of Kent at Canterbury. In the 1990s, she carried out doctoral research on Cambodian history and political economy. Her research on Cambodia has been published in French and in English. Her current research aims at testing the universality of the Records Continuum Model through its application to archives that have undergone radical transformations either for political or social reasons. She was part of the Organising Committee for the International Conference on the History of Records and Archives (I-CHORA 8), which was held at Monash University in May 2018. She is also General Editor of Archives and Manuscripts, the journal of the Australian Society of Archivists.

Fiorella Foscarini is Associate Professor in the Faculty of Information at the University of Toronto (CA). She holds a Ph.D. in Archival Studies from the University of British Columbia, Vancouver (CA) and also taught with the University of Amsterdam (NL). Before joining academia, she worked as an archivist and a records manager for the European Central Bank in Frankfurt am Main (DE) and the Province of Bologna (IT). She was a member of the Program and Organising Committees for the latest two editions of the International Conference on the History of Records and Archives (I-CHORA 7 and I-CHORA 8), which took place in Amsterdam (NL) in 2015 and Melbourne (AU) in 2018, respectively. She currently serves as General Editor of Archivaria and Co-editor of the Records Management Journal. 